\title{
Alcohol Tolerance in Large-Conductance, Calcium-Activated Potassium Channels of CNS Terminals Is Intrinsic and Includes Two Components: Decreased Ethanol Potentiation and Decreased Channel Density
}

\author{
Andrzej Z. Pietrzykowski, ${ }^{1}$ Gilles E. Martin, ${ }^{1}$ Sylvie I. Puig, ${ }^{1}$ Thomas K. Knott, ${ }^{2}$ Jose R. Lemos, ${ }^{2}$ and \\ Steven N. Treistman ${ }^{1}$ \\ Departments of ${ }^{1}$ Neurobiology and ${ }^{2}$ Physiology, University of Massachusetts School of Medicine, Worcester, Massachusetts 01605
}

\begin{abstract}
Tolerance is an important element of drug addiction and provides a model for understanding neuronal plasticity. The hypothalamicneurohypophysial system (HNS) is an established preparation in which to study the actions of alcohol. Acute application of alcohol to the rat neurohypophysis potentiates large-conductance calcium-sensitive potassium channels (BK), contributing to inhibition of hormone secretion. A cultured HNS explant from adult rat was used to explore the molecular mechanisms of BK tolerance after prolonged alcohol exposure. Ethanol tolerance was intrinsic to the HNS and consisted of: (1) decreased BK potentiation by ethanol, complete within 12 min of exposure, and (2) decreased current density, which was not complete until $24 \mathrm{hr}$ after exposure, indicating that the two components of tolerance represent distinct processes. Single-channel properties were not affected by chronic exposure, suggesting that decreased current density resulted from downregulation of functional channels in the membrane. Indeed, we observed decreased immunolabeling against the BK $\alpha$-subunit on the surface of tolerant terminals. Analysis using confocal microscopy revealed a reduction of BK channel clustering, likely associated with the internalization of the channel.
\end{abstract}

Key words: addiction; alcohol; ethanol; explant; tolerance; BK channel; terminals

\section{Introduction}

Tolerance represents an important component of drug addiction. Various forms of tolerance (e.g., acute, chronic) are defined by their time course (Kalant, 1998). The hypothalamic-neurohypophysial system (HNS), responsible for the release of the peptide hormones vasopressin (AVP) and oxytocin (OXT), has proven to be a useful preparation to study the acute and chronic actions of alcohol, including tolerance. The effects of ethanol on channel function in this system have important physiological and behavioral consequences, resulting from the wide-ranging central and peripheral actions of AVP and OXT (Lemos, 2001). One target of alcohol action in neurohypophysial terminals is the large-conductance, calcium-activated potassium channel (BK) (Marty, 1981; Dopico, 1996). The enhancement of BK activity by acute ethanol is linked to inhibition of AVP and OXT secretion (Knott et al., 2002). Chronic exposure of rats to an alcohol-

Received April 22, 2004; revised July 23, 2004; accepted Aug. 11, 2004.

This work was supported by National Institutes of Health Grant AA08003 (S.N.T.). We thank Paula FeinbergZadek, Noreen Rossi, and Hector Marrero for helpful comments on the explant preparation, Harold Gainer for G38 and G41 antibodies, Thomas Schoenfeld for his assistance and use of stereological equipment, Robert 0'Connell and David Stevens for assistance in statistical analysis, and members of Jose Lemos' and our research groups for insightful discussions.

Correspondence should be addressed to Steven Treistman, Department of Neurobiology, University of Massachusetts Medical School, 364 Plantation Street, Worcester, MA 01605. E-mail: steven.treistman@umassmed.edu. DOI:10.1523/JNEUROSCI.1536-04.2004

Copyright $\odot 2004$ Society for Neuroscience $\quad$ 0270-6474/04/248322-11\$15.00/0 containing diet for 3 weeks results in the development of tolerance in the HNS, consisting of a reduced acute effect of ethanol on hormone secretion from the neurohypophysial $(\mathrm{NH})$ terminal (Knott et al., 2000), concurrent with the decreased ethanol potentiation of BK channels and decreased BK current density in terminals (Knott et al., 2002).

Although significant progress toward understanding the molecular mechanisms of tolerance in the HNS has been made, the use of the whole animal has been limiting. First, studies of the chronology of tolerance, using the sucrose fade technique, are impeded by the period necessary for the establishment of consistent blood alcohol levels (Knott et al., 2000). Use of the HNS explant allows precise control over dosage and time of exposure to exogenous agents (Rossi, 2004; Somponpun and Sladek, 2004). Second, it is impossible to separate actions of the drug directly on neurons within the HNS from actions of elements originating outside of the HNS, but influencing these neurons. The molecular mechanisms of tolerance have been described, analogously to the neurobiology of learning, in terms of intrinsic and extrinsic tolerance. Neurons exhibiting intrinsic tolerance encode compensatory changes in their molecular machinery, as a response to drug exposure. The use of the HNS explant allows us to directly test for the presence of intrinsic tolerance within the HNS release machinery. Finally, because the last period of HNS development takes place postnatally (Choy and Watkins, 1979; Chevaleyre et al., 2001), HNS explants harvested from adult an- 
imals avoid complications from the influence of chronic exposure on development.

We demonstrate two distinct components of intrinsic tolerance: decreased potentiation by alcohol evident within $12 \mathrm{~min}$ of exposure, and a decrease in current density that develops over a $24 \mathrm{hr}$ period. Single-channel recordings indicate that conductance of the channel is not changed in the tolerant terminals, suggesting that the decrease in current density corresponds to a diminished number of channels in the membrane. This is corroborated by immunohistochemical studies showing decreased channel labeling on the surface of tolerant terminals. Moreover, quantitative analysis revealed a change in the expression pattern from cluster-type in naive terminals to a diffuse pattern in tolerant terminals.

Preliminary data were presented in an abstract form (Pietrzykowski et al., 2001, 2003).

\section{Materials and Methods \\ Explant preparation and culture}

Male Sprague Dawley adult rats (3-5 weeks old) were obtained from Taconic Farms (Germantown, NY). All procedures were performed in accordance with the National Institutes of Health guidelines on the Care and Use of Animals and study protocol approved by the University of Massachusetts Animal Care and Use Committee. After decapitation, the brain and pituitary with intact pituitary stalk were removed very rapidly from the skull and chilled in oxygenated dissection buffer (in mM): 120 $\mathrm{NaCl}, 5 \mathrm{KCl}, 1.0 \mathrm{MgCl}_{2}, 1.9 \mathrm{CaCl}_{2}, 2.0$ EGTA, 10 HEPES, $5.0 \mathrm{NaHCO}_{3}$, 15.0 glucose, 0.5 glutamine (Glutamax; Invitrogen, Gaithersburg, MD), and $100 \mathrm{U} / \mathrm{ml}$ to $0.1 \mathrm{mg} / \mathrm{ml}$ penicillin-streptomycin (Invitrogen), $\mathrm{pH}$ $7.2,310 \mathrm{mOsm}$. To increase cell survival, dissection buffer contained: (1) low levels of free calcium ( $3 \mu \mathrm{M})$, (2) B27 supplement with antioxidants (1:50; Invitrogen), and (3) $1 \mathrm{~mm}$ nitro-arginine and kynurenic acid. Under a dissection microscope, the anterior pituitary was removed, and a hexagonal block of tissue was carved out (by cutting rostral to the optic chiasm, parallel to the optic tract, lateral to the median eminence and caudal to the stalk, and undercutting at a depth of 1-2 mm). Next, tissue was trimmed to the final thickness of $550-650 \mu \mathrm{m}$ to enable nutrients and oxygen penetration despite the lack of vascular perfusion (Fujii et al., 1982; Nicholson and Hounsgaard, 1983). Explants were cultured individually in a humidified incubator, at $34^{\circ} \mathrm{C}$, in $5 \% \mathrm{CO}_{2}$, on Millicell $\mathrm{CM}$ inserts (Millipore, Bedford, MA), placed in Petri dishes (60 mm; Corning, Corning, NY). They were cultured in Neurobasal A medium (310 mOsm) with B27, glutamine, penicillin-streptomycin (as in dissection buffer), and $10 \%$ fetal calf serum (FCS; Sigma, St. Louis, MO) in the air-medium interface (Stoppini et al., 1991; Brewer, 1997; House et al., 1998; Xiang et al., 2000). Medium was changed on the day after dissection to ethanol-free medium (naive group) or medium containing $20 \mathrm{~mm}$ ethanol (chronic group). The control (uncultured) group was immediately fixed after isolation.

\section{Ethanol treatment}

A constant ethanol concentration was maintained by placing an open dish with $20 \mathrm{~mm}$ ethanol near the dish containing the ethanol-treated explant, in a closed, but not sealed container, which allowed exchange of gases. Ethanol levels measured in both the media and the tissue, using an NAD-ADH kit (Sigma) according to manufacturer's instructions, indicated a constant level of $20 \mathrm{~mm}$ ethanol at all exposure times tested $(0.5$, $1,3,6$ and $24 \mathrm{hr}$ ). For exposures $<30 \mathrm{~min}$, terminals were dispersed first and then exposed to ethanol during electrophysiological recording.

\section{Viability assay}

Immunostaining. Explants were fixed in 4\% paraformaldehyde (PFA). After immersion in $20 \%$ sucrose, explants were embedded in $6 \%$ gelatinegg yolk mixture in cardboard molds, and exposed to concentrated formaldehyde vapors for at least $3 \mathrm{~d}\left(4^{\circ} \mathrm{C}\right)$. After hardening, $60 \mu \mathrm{m}$ sections were cut on a freezing microtome, and sections were placed in Net-well carriers. The floating sections were permeabilized and blocked and incubated alternately with the primary monoclonal mouse antibodies: G38 (against AVP-neurophysin) or G41 (anti-OXT-neurophysin) (1:300; a gift from H. Gainer, Laboratory of Neurochemistry, National Institute on Neurological Disorders and Stroke, National Institutes of Health, Bethesda, MD) (Ben Barak et al., 1985; Whitnall et al., 1985). Next, sections were incubated with Alexa 488-tagged, anti-mouse secondary antibody (Molecular Probes, Eugene, OR), counterstained with Hoechst dye (1:5000), and mounted on microslides (SuperFrost Plus; VWR Scientific, West Chester, PA) in Prolong Antifade medium (Molecular Probes). Alternatively, sections were incubated with biotinylated secondary antibody, processed using Vectastain Elite $\mathrm{ABC}$ kit and Peroxidase Substrate kit (Vector Laboratories, Burlingame, CA), counterstained with Hematoxylin QS (Vector Laboratories), dehydrated with ascending alcohols, cleared with xylene, and mounted in VectaMount (Vector Laboratories).

Unbiased stereological determination of magnocellular neuron viability. An unbiased stereological technique (West et al., 1991) was used to estimate the total number of AVP and OXT neurons in the supraoptic nucleus (SON) and its retrochiasmatic part (SONr). All stereological analyses were performed using Stereo Investigator 4.33 (MicroBrightField, Colchester, VT) and a Leica DMRE microscope (Deerfield, IL). We used 18 ( $n=6$ for each group) supraoptic nuclei in the analysis. All sections were alternately stained against AVP or OXT (starting randomly with either AVP or OXT antibodies), and AVP- or OXT-positive magnocellular cell bodies were counted. Healthy cells had large cell bodies $(\sim 40$ $\mu \mathrm{m}$ diameter) filled with hormone, with long processes and a large nonpyknotic nucleus. Magnocellular neurons with shrunken cytoplasm and/or pyknotic nuclei were considered apoptotic (Vutskits et al., 1998). Apoptotic cells constituted $<3 \%$ of neurons in each group and were not included in the final cell number. Estimates of the total number of neurons were generated by the Stereo Investigator using a fractionator correction factor of 7.42. Differences between left and right nuclei were negligible. Sampling was performed to maintain a coefficient of error $<10 \%$ (Gundersen and Jensen, 1987; Gundersen et al., 1999).

\section{NH terminal preparation}

Neurohypophysial terminals were homogenized as previously described (Cazalis et al., 1987) in a solution containing $270 \mathrm{~mm}$ sucrose, $10 \mathrm{~mm}$ HEPES, and 1 mM EGTA, pH 7.3. The homogenate was then plated onto a poly-D-lysine-coated $35 \mathrm{~mm}$ polystyrene dish or a coverslip, and after attachment, terminals underwent electrophysiological measurements or immunocytochemistry.

\section{Electrophysiology}

Dissociated terminals were identified by their spherical shape, size (2-8 $\mu \mathrm{m}$ in diameter), lack of nuclei, and golden color under Hoffmannphase contrast optics. First they were bathed in ethanol-free low-calcium $\left(3 \mu \mathrm{M}\right.$ ) Locke's solution (in mM: $142 \mathrm{NaCl}, 2.0 \mathrm{KCl}, 2.0 \mathrm{CaCl}_{2}, 2.0 \mathrm{MgCl}_{2}$, 13.0 glucose, and 15.0 HEPES, pH 7.3, $305 \mathrm{mOsm}$ ), which subsequently was changed into ethanol-free normal calcium Locke's solution $(2.2 \mathrm{mM}$ $\mathrm{CaCl}_{2}$, no EGTA). Average time before ethanol challenge was $60 \mathrm{~min}$.

\section{Whole-cell recordings}

Electrodes were pulled from thin-walled borosilicate glass (Drummond Scientific, Broomall, PA) on a vertical puller (David Kopf Instruments, Tujunga, CA) and fire-polished (Narashige, Tokyo, Japan) to give a final resistance of 5-10 M $\Omega$ (2-4 M $\Omega$ for perforated patch) when filled with pipette solution (in mM): 120.0 potassium gluconate, 15.0 HEPES, 2.2 $\mathrm{CaCl}_{2}, 1.0 \mathrm{MgCl}_{2}, 4.0$ EGTA, and 4.0 HEDTA, pH 7.35, $305 \mathrm{mOsm}(\sim 4.0$ $\mu \mathrm{M}$ free $\mathrm{Ca}^{2+}$ ). For perforated patch technique, $30 \mu \mathrm{M}$ amphotericin $\mathrm{B}$ was added to the pipette solution ( 120.0 potassium gluconate, $15.0 \mathrm{KCl}$, $10 \mathrm{HEPES}, 2.2 \mathrm{CaCl}_{2}$, and $\left.1.0 \mathrm{MgCl}_{2}, \mathrm{pH} 7.3,295 \mathrm{mOsm}\right)$. Currents were recorded using an Axopatch 200B (Axon Instruments, Foster City, CA) or a Dagan amplifier at a sampling rate of $1-5 \mathrm{kHz}$ and leak-subtracted on line. Series resistance never exceeded $15 \mathrm{M} \Omega$ and was compensated. Data were acquired and analyzed with pClamp6 (Axon Instruments).

\section{Single-channel recordings}

Unitary current recordings were obtained from excised, inside-out patches using standard patch-clamp techniques. Currents were recorded in symmetrical $135 \mathrm{~mm} \mathrm{~K}^{+}$using a patch-clamp amplifier (Axopatch 200; Axon Instruments) at a sampling rate of $5 \mathrm{kHz}$ and filtered at $1 \mathrm{kHz}$ 
using an eight pole Bessel filter. Data were acquired and analyzed using pClamp 6.02 software.

\section{Superfusion and drug application}

Terminals in whole-cell configuration or patches excised from the membrane were exposed to $5 \mu \mathrm{M}\left[\mathrm{Ca}^{2+}\right]_{\text {free }}$ control solution flowing from a micropipette ( $1 \mathrm{~mm}$ diameter; WPI, Sarasota, FL), and the potential across the membrane was set to produce a relatively low open probability $\left(N P_{\mathrm{o}} \sim 0.2\right)$. BK channel activity was recorded for $30 \mathrm{sec}$, and then patches were superfused with ethanol and washed. Because chronic ethanol exposure reduces BK potentiation by subsequent acute ethanol challenge (Knott et al., 2002), we used a high (100 $\mathrm{mm}$ ) ethanol concentration for acute challenge, to ensure a measurable ethanol effect. When studying gating properties of the BK channel, the intracellular surface of patches was exposed to solutions with a final $\left[\mathrm{Ca}^{2+}\right]_{\text {free }}$ of 1,5 , and $10 \mu \mathrm{M}$. The calculation of $\left[\mathrm{Ca}^{2+}\right]_{\text {free }}$ was computed using a custom-written program, based on calculations by Fabiato (1988). At each potential, channel activity was recorded for $30 \mathrm{sec}$.

In the perforated patch configuration, BK current was isolated by adding 4-aminopyridine to the bath ( $7 \mathrm{~mm}$ final concentration) to block the fast inactivating $\left(I_{\mathrm{A}}\right)$ potassium current (Thorn et al., 1991; Knott et al., 2002). Baseline current was first established by stepping from the holding potential of $\sim 90 \mathrm{mV}$ to $+40 \mathrm{mV}$, for $500 \mathrm{msec}$, with a15 sec recovery interval between steps. During ethanol application, BK current was determined by averaging a set of four traces obtained within each minute. Ethanol potentiation of the BK current was expressed as a percentage above the baseline level.

\section{Data analysis}

$N P_{\text {o }}$ was determined in the presence of $10 \mu \mathrm{M}$ $\mathrm{Ca}^{2+}$ and was used as an index of channel activity. $N P_{\mathrm{o}}$ values were calculated from allpoints amplitude histograms by fitting the histogram with a sum of Gaussian functions using a Levenberg-Marquardt algorithm. $N P_{\mathrm{o}}$ data as a function of voltage were fitted with a Boltzmann function of the type: $P_{\mathrm{o}}=(1+\exp -$ $\left.K\left(V-V_{0.5}\right)\right)^{-1}$, where $K$ is the logarithmic potential sensitivity and $V_{0.5}$ the potential at which $P_{\mathrm{o}}$ is half-maximal. When the $N P_{\mathrm{o}}$-voltage relationship is fitted by a Boltzmann curve, a plot of $\ln N P_{\mathrm{o}}$ versus voltage is linear at low values of $P_{\mathrm{o}}$ (Dopico et al., 1996, 1998). In this plot, the reciprocal of the slope is the potential needed to produce an $e$-fold change in $N P_{\mathrm{o}}$, which is routinely used to measure the voltage dependence of BK channel gating.

The relationship between $\left[\mathrm{Ca}^{2+}\right]_{\mathrm{i}}$ and the channel steady-state $P_{\mathrm{o}}$ is usually a sigmoid function that can be fitted according to a Hill equation: $P_{\mathrm{o}}=P_{\max }\left[\mathrm{Ca}^{2+}\right]_{\mathrm{i}}{ }^{n \mathrm{H}} /\left(\mathrm{K}+\left[\mathrm{Ca}^{2+}\right]_{\mathrm{i}}{ }^{n \mathrm{H}}\right)$ where $P_{\mathrm{o}}$ is the steady-state open probability, $P_{\max }$ is the maximum open probability, $n^{\mathrm{H}}$ is the slope factor (or Hill coefficient), and the $n$th root of $K$ gives an estimate of the midpoint of the activation curve and the sensitivity of the channel to $\left[\mathrm{Ca}^{2+}\right]_{\mathrm{i}}$. The slope factor provides a minimum estimate of the number of $\mathrm{Ca}^{2+}$ ions involved in maximally activating the channel (McManus, 1991). Thus, the required $\left[\mathrm{Ca}^{2+}\right]_{\mathrm{i}}$ to achieve the midpoint of activation $\left(P_{0.5}\right)$ at $0 \mathrm{mV}$, usually designated $\left[\mathrm{Ca}^{2+}\right]_{0.5}$, is a widely used parameter to measure the calcium sensitivity of BK channels.

Duration of open times was measured with half-amplitude threshold analysis. Mean open time was calculated based on an equation: $T_{\mathrm{o}}=$

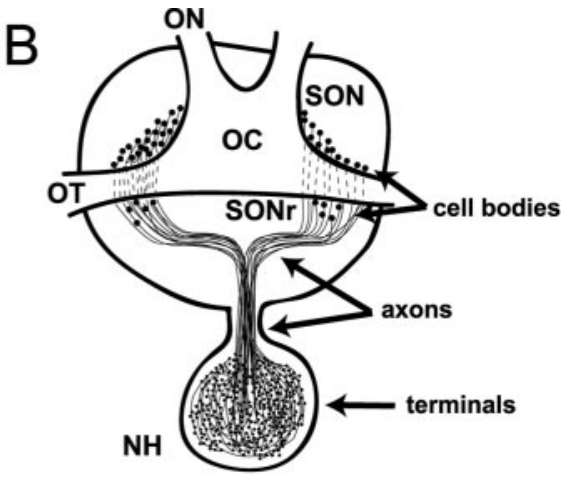

D
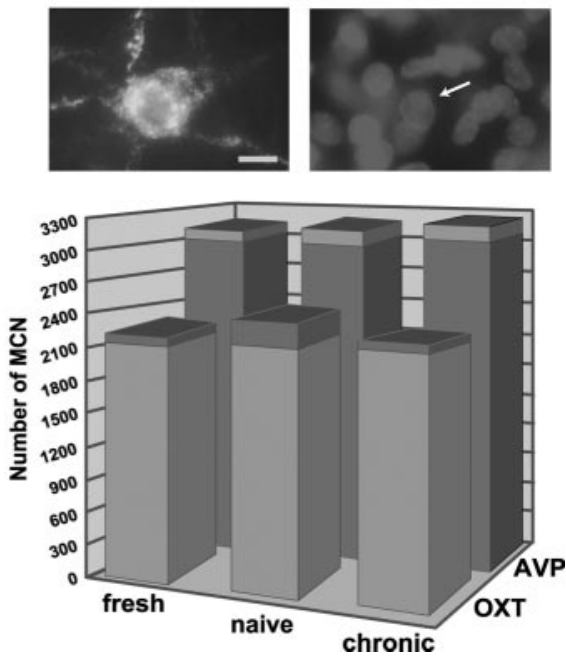

HNS explant contains viable AVP and OXT neurons of the intact SON-NH. A, Bright-field top view of an HNS explant. below the sole of the third ventricle, through the median eminence to the neurohypophysis. D, Magnocellular neurons in SON were 列 to estimate the viability of the HNS explants. Representative immunofluorescent grayscale images (top) of AVP neuron in large cell body with long processes filled with hormone (left image) and large, nonapoptotic nucleus with diffuse Hoechst staining (right image, arrow). Other neurons are not visible because of their out-of-focus location. The exact number of neurons in SON was estimated using stereological techniques (see Material and Methods) and is shown in the graph (bottom). Cap on each bar represents SD. ME, Median eminence; MM, medial mammilliary nucleus; PVN, paraventricular nucleus; 3V, third ventricle. Scale bars: $A, 1.5 \mathrm{~mm} ; C, 430 \mu \mathrm{m} ; D, 20 \mu \mathrm{m}$.

$N P_{\mathrm{o}} T / X_{\mathrm{o}}$ for multiple channel recordings $\left[N=\right.$ number of channels; $P_{\mathrm{o}}$ $=$ open probability; $T=$ time of observation (in milliseconds); $X_{\mathrm{o}}=$ number of openings]. A maximum-likelihood minimization routine was used to fit curves to the distribution of open times. Determination of the minimum number of terms for adequate fit was established using a standard $F$ statistic table (significance level, $p<0.01$ ). The unitary conductance $(\gamma)$ was taken as the slope of the unitary current amplitude-voltage relationship. Values for unitary current were obtained from the Gaussian fit of all-points amplitude histograms by measuring the distance between the modes corresponding to the closed state and the first opening level. For all experiments, voltages given correspond to the potential at the intracellular side of the membrane.

\section{Immunocytochemistry, confocal analysis, and quantification of}

BK expression

Terminals were isolated as described above, fixed in 2\% PFA, and double-labeled using mouse antibodies against AVP (or OXT) and rabbit antibodies against BK channel $\alpha$ subunit (1:200; Affinity Bioreagents, Golden, CO) and secondary antibodies (anti-mouse Alexa 594, anti- 


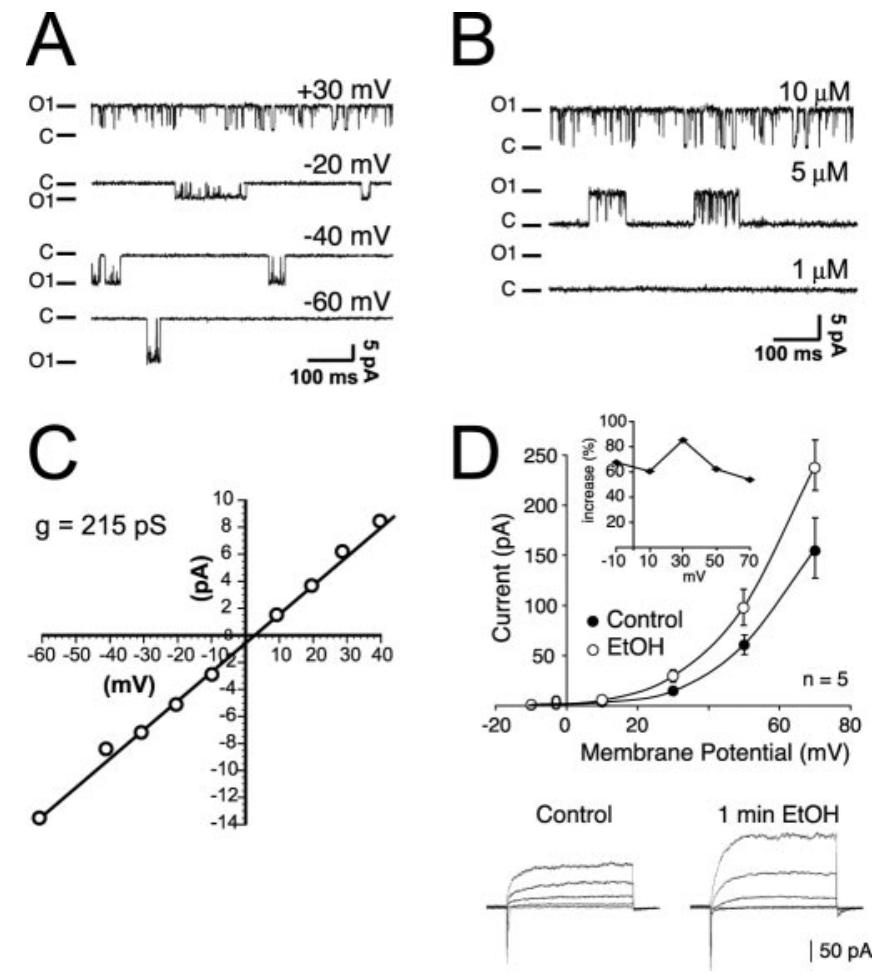

Figure 2. Voltage and calcium dependence of BK channels in naive NH terminals. A, Representative currents from a single BK channel, recorded in an inside-out patch at different potentials in the presence of $10 \mu \mathrm{m}$ free $\left[\mathrm{Ca}^{2+}\right]_{\mathrm{i}}$. Channel activity increases as the patch membrane is held at more depolarized potentials. B, Activity of a single BK channel as in $A$ recorded at +30 $\mathrm{mV}$ in the presence of various $\left[\mathrm{Ca}^{2+}\right]_{\mathrm{i}}$. The activity increases as the cytosolic face of the channel is exposed to increasing concentrations of calcium. C and $0_{1}$, adjacent to the traces, indicate the closed and the open states, respectively. C, Unitary conductance was determined by fitting the I-V relationship by linear regression. D, Ethanol-mediated potentiation of BK current is voltageindependent. Graph shows the average BK current amplitude $(n=5)$ as a function of the membrane voltage measured in whole-cell voltage clamp. Each terminal served as its own control. A $50 \mathrm{~mm}$ concentration of ethanol increased BK current amplitude at all the potentials tested between -10 and $+70 \mathrm{mV}$ in a voltage-independent manner (inset). Representative traces show BK currents recorded from a naive terminal and evoked at different membrane potentials ( $20 \mathrm{mV}$ steps) before (control) and after $50 \mathrm{~mm}$ ethanol application. The fast transient current at the beginning of the voltage pulse is caused by sodium channels (TTX was omitted from the bath solution).

rabbit Alexa 488, respectively; Molecular Probes). Coverslips were then mounted to microslides (SuperFrost Plus; VWR Scientific) using Prolong Antifade medium (Molecular Probes). Laser-scanning fluorescence and differential interference contrast images were acquired simultaneously using a Leica laser-scanning microscope. The laser power was set to avoid photobleaching. Intensity of the signal assessed before and after capturing of images showed no decrease or saturation. AVP and OXT terminals of similar size (average: $3.31 \pm 0.36 \mu \mathrm{m}$ ) were scanned using six to eight $Z$-sections (average: $420 \pm 30.0 \mathrm{~nm} / \mathrm{step}$ ). Using Leica software (version 2.00; Microsystems, Heidelberg, Germany), two to four middle sections of each terminal were selected for the analysis. Stacks of images were saved as TIFF files and analyzed off-line. The number of BK clusters, their size, and the intensity profiles were determined. The intensity of specific BK staining in the terminals was calculated by subtracting average background intensity ( $<1 \%$ of the specific staining), obtained from three nonfluorescent areas. The quantitative analysis was performed blind using a Photoshop-based (Adobe Systems, San Jose, CA) protocol. Each section of the terminal was divided into a membrane region and an interior region, using the assumption that the membraneassociated fluorescent signal has a width of $0.45 \mu \mathrm{m}$ (Chiu et al., 2002). Boundaries of regions were determined using the DIC image of the terminal overlapped onto the BK expression image. In control experiments using antibodies preincubated with the antigenic peptides, we observed no specific staining.

\section{Statistics}

Unless otherwise indicated, statistical significance between the various treatment groups was analyzed using Student's $t$ test (Statistica, version 5.5; StatSoft, Tulsa, OK). All data are expressed as mean \pm SEM, and $p$ values $<0.05$ were considered to be statistically significant.

\section{Results \\ HNS explants contain viable AVP and OXT magnocellular neurons with intact axons}

Because of the nonplanar route of axons from the SON to the $\mathrm{NH}$ (Silverman and Zimmerman, 1983; Armstrong, 1995), it is not possible to prepare an intact HNS explant using a straight slice technique. Thus, it was necessary to "sculpt" the tissue manually with microtools, using caution to avoid axotomy. The resulting HNS explants were laid on Millipore CM inserts, in Petri dishes in the interface between medium and air. An image of an actual HNS explant is shown in Figure $1 A$. Elements of the optic system [optic nerves $(\mathrm{ON})$, optic chiasm (OC), optic tract $(\mathrm{OT})$ ] are apparent and were used as landmarks in assessing the position of the supraoptic nuclei (marked as SON and SONr for the retrochiasmatic part of the SON), where cell bodies of the neurons of interest are located (Fig. $1 \mathrm{~B}$ ). To ensure that the axonal tract was intact in the HNS explant, we performed immunofluorescent staining using antibodies against AVP and OXT. A semi-sagittal section of the AVP-stained explant in Figure $1 C$ confirms that the axonal path from cell bodies to terminals was well preserved in the explant. Similar results were obtained for OXT-containing neurons (data not shown).

\section{Chronic, low-dose ethanol treatment does not influence magnocellular neuron viability}

High doses of ethanol ( $\sim 100 \mathrm{~mm})$ are known to trigger neuronal apoptosis (Madeira et al., 1993; Ruela et al., 1994), therefore we limited our chronic exposure to clinically relevant $(20 \mathrm{~mm})$ concentrations. In exposures of $\geq 30 \mathrm{~min}$, ethanol penetrated the tissue of the HNS explant and was maintained at a constant 20 $\mathrm{mm}$ level throughout the treatment. Viability of magnocellular neurons was unaffected by $48 \mathrm{hr}$ culture with or without $24 \mathrm{hr}$ ethanol treatment (Fig. 1D). Viable AVP and OXT magnocellular neurons have large cell bodies and processes filled with hormone. Using Hoechst dye, we observed viable cells, in which the large, weakly stained nuclei with loosely coiled chromatin suggested the absence of apoptosis (Bonde et al., 2002). Many neurons with these features were observed in the HNS explant. An example of such a cell is shown in Figure $1 D$. To precisely determine the influence of culturing and ethanol exposure on survival of AVP and OXT magnocellular neurons, we used stereology to assess the number of viable neurons. In freshly isolated tissue (Fig. $1 D$, graph) the SON contained $3080 \pm 42$ AVP neurons and a slightly smaller number of OXT neurons $(2170 \pm 38)$, in accordance with previous reports (Swaab et al., 1975; Rhodes et al., 1981; Marciano et al., 1989; Harding et al., 1995; House et al., 1998; Burbach et al., 2001). Explants cultured in ethanol-free medium contained $2996 \pm 78$ AVP cells and $1979 \pm 118$ OXT cells, whereas explants cultured in $20 \mathrm{~mm}$ ethanol contained $3136 \pm 76$ AVP and $1993 \pm$ 35 OXT-positive cells, respectively. Apoptotic, hormone-positive (AVP or OXT) cells constituted $<3 \%$ of the total number of SON neurons in fresh explants, as well as in explants cultured in the 
presence or absence of ethanol. Thus, we did not observe increased cell death during culture or after ethanol exposure.

BK channels retain normal properties in cultured HNS explant

Figure $2 A$ shows typical single-channel recordings from an inside-out patch from a $\mathrm{BK}$ channel in a $\mathrm{NH}$ terminal from a naive explant. We tested the voltage dependence of this channel by exposing its intracellular face to $5 \mu \mathrm{M}$ free $\mathrm{Ca}^{2+}$ and changing the holding potential. At $-60 \mathrm{mV}$, the $\mathrm{BK}$ channel remained mostly in a closed state and showed only brief openings. As more depolarized potentials $(-40$ and $-20 \mathrm{mV}$ ) were reached, the time spent in the open state increased (Fig. 2A). We also tested the calcium dependence of BK channels by holding the membrane potential at +30 $\mathrm{mV}$ and exposing the cytoplasmic face of the channel to increasing $\mathrm{Ca}^{2+}$ concentrations (Fig. $2 \mathrm{~B}$ ). In the presence of $1 \mu \mathrm{M}$ $\mathrm{Ca}^{2+}$, the BK channel showed only sporadic openings. After switching to $5 \mu \mathrm{M}$ $\mathrm{Ca}^{2+}$, channel activity increased, to finally reach near maximum open probability in $10 \mu \mathrm{M} \mathrm{Ca}^{2+}$. Finally, a unitary conductance of 215 pS, a value typical of BK channels, was observed in symmetrical $135 \mathrm{~mm}$ $\mathrm{K}^{+}$(Fig. 2C). Thus, BK channel basic properties (Wang et al., 1992; Dopico et al., 1996, 1999a) remained unchanged during HNS explant preparation or culture. We also examined the dependence of ethanol effects on the membrane potential between -10 and $+70 \mathrm{mV}$ (Fig. 2D) in whole-cell recordings. We found that 50 $\mathrm{mM}$ ethanol potentiated BK currents at all potentials tested (Fig. 2D) and that this effect was voltage-independent (Fig. 2D, inset). Traces in Figure $2 D$ show representative ethanol-mediated potentiation of BK currents recorded from a naive terminal and evoked at different membrane potentials ( $20 \mathrm{mV}$ steps) before (control) and after $50 \mathrm{~mm}$ ethanol application.

\section{BK channel tolerance to ethanol in terminals is intrinsic}

Next, we examined whether $24 \mathrm{hr}$ chronic ethanol treatment of the explant produces changes in BK channel properties similar to those observed in terminals obtained from animals on an ethanol diet (Knott et al., 2002). First, we compared the effect of ethanol on BK channels isolated from fresh terminals to BK channels obtained from explants cultured in ethanol-free medium. Ethanol increased the open probability of BK channels from freshly isolated terminals and did not change channel unitary current amplitude (Fig. 3A, top panels), in agreement with previous findings (Dopico et al., 1996). After $2 \mathrm{~d}$ in culture in ethanol-free medium, BK ethanol potentiation was unaltered (Fig. $3 A$, middle panels). On average, ethanol increased BK channel open probability by more than fivefold (Fig. $3 B)(5.26 \pm 1.87 ; n=7)$. Interestingly, $24 \mathrm{hr}$ of $20 \mathrm{~mm}$ ethanol treatment of the explant pro-
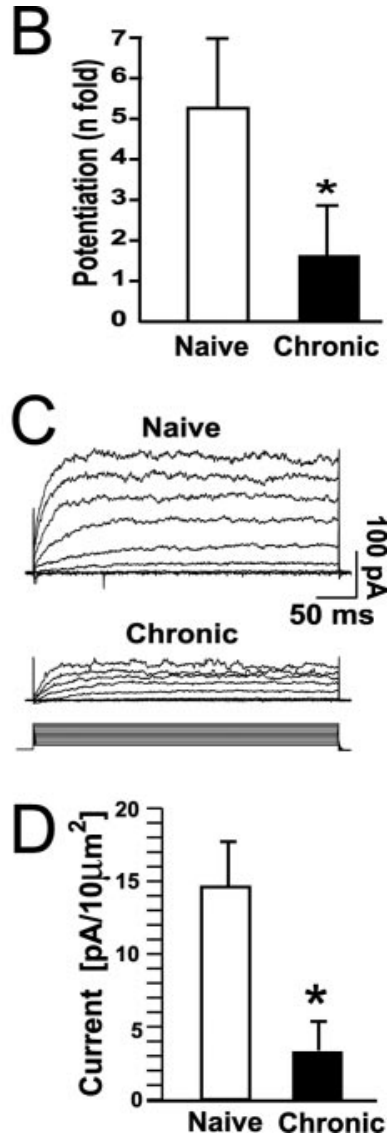

Figure 3. BK channels exhibit intrinsic tolerance to ethanol after $24 \mathrm{hr}$. $A$, Effects of acute ethanol in freshly isolated, naive, and chronic explants. Inside-out terminal patches were exposed to $5 \mu \mathrm{m}$ free- $\mathrm{Ca}^{2+}$ control solution, and the potential across the as shown in representative traces at the left of each panel. All-points amplitude histograms summarizing these effects are shown 作 application $\left(N P_{0 \text { EtoH }} / N P_{0}\right.$ Control $)$, where $1=$ no potentiation. Chronic ethanol treatment decreases BK channel potentiation by ethanol ( $p<0.05$ ) compared with the naive group. C, BK currents in terminals were recorded in whole-cell patch clamp to

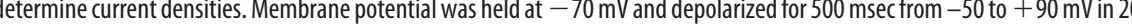
$\mathrm{mV}$ increments. $D$, Average current densities ( \pm SEM) recorded in naive $(n=5)$ and chronic $(n=4)$ terminals were significantly smaller ( $\sim$-fold) after chronic ethanol exposure. Current densities are expressed as picoamperes per $10 \mu \mathrm{m}^{2}$ (membrane capacitance was used to assess membrane area).

duced significantly reduced BK channel potentiation by acute ethanol challenge $(1.7 \pm 1.1$-fold; $n=12)$ (Fig. $3 A$, bottom panels, $B)(p<0.001)$.

In addition to the decreased potentiation by acute drug challenge, BK current densities obtained in terminals from explants exposed to ethanol for $24 \mathrm{hr}$ were significantly lower than in terminals from naive explants. In terminals from naive explants, depolarizing the membrane to $+50 \mathrm{mV}$ (from $-70 \mathrm{mV}$ ) evoked a strong BK current (196 $\pm 43 \mathrm{pA})$. In contrast, after $24 \mathrm{hr}$ ethanol treatment, a similar voltage step elicited only $56 \pm 36 \mathrm{pA}$ of $\mathrm{BK}$ current (Fig. 3C). When current was expressed as a function of membrane surface area (determined by membrane capacitance), we found a dramatic decrease in current density after chronic ethanol treatment, from $14.2 \pm 3 \mathrm{pA} / 10 \mu \mathrm{m}^{2}(n=5)$ in naive explants to $2.71 \pm 2 \mathrm{pA} / 10 \mu \mathrm{m}^{2}(n=4)$ in chronic explants $(p<0.05)$ (Fig. 3D).

Thus, chronic tolerance to ethanol observed in neurohypoph- 
ysial terminals from cultured explants was intrinsic and did not require the actions of elements originating outside of the HNS.

\section{Time course of tolerance suggests two distinct processes}

We next determined the time course, beginning at $30 \mathrm{~min}$, of the two components of tolerance evident at $24 \mathrm{hr}$. Macroscopic currents in terminals from HNS explants cultured for various periods of time in ethanol were obtained, using whole-cell patch clamp recordings. Two distinct time courses were observed. A rapid reduction in $\mathrm{BK}$ ethanol potentiation was evident within 30 min of drug exposure and was sustained for the $24 \mathrm{hr}$ test period, whereas BK current density responded more slowly to the ethanol treatment, showing partial reduction in current density after $6 \mathrm{hr}$ of ethanol exposure, and reaching a near-minimal value after $24 \mathrm{hr}$ (Fig. 4A). The finding that decreased potentiation was already fully present at the $30 \mathrm{~min}$ time point led us to examine the development of this form of tolerance during the first few minutes of ethanol exposure. Because short-latency changes might be complicated by a time lag attributable to ethanol penetration into the explant, we altered the protocol, to examine the reduction of ethanol potentiation of BK current during continued exposure to ethanol using the perforated patch clamp technique of an isolated terminal from an ethanol-naive rat. It is evident (Fig. $4 B$ ) that potentiation is decreasing within 4 min of drug exposure, and this form of tolerance is fully developed by $12 \mathrm{~min}$ of exposure. Introduction of an incremental $50 \mathrm{~mm}$ ethanol (final concentration, $100 \mathrm{~mm}$ ) at the $13 \mathrm{~min}$ time point did not result in the reinitiation of potentiation (data not shown). Representative traces are shown in Figure $4 C$.

\section{Single-channel properties of BK remain unchanged after} chronic ethanol treatment

The observed decrease in current density could result from either altered individual channel properties or from a downregulation of functional channels (or both). We tested the first possibility by examining gating properties, kinetics, and conductance of terminal BK channels from naive and chronic ( $24 \mathrm{hr}$ ethanol exposure) explants.

\section{Voltage and calcium activation}

Figure $5 \mathrm{~A}$ shows that the open probability of BK channels obtained from naive (open markers) and chronic (filled markers) terminals, as a function of calcium concentrations and voltage, does not differ. In both groups, for each $\left[\mathrm{Ca}^{2+}\right]_{\mathrm{i}}$ the $N P_{\mathrm{o}}$-voltage relationship could be well fitted with a sigmoid function (see Materials and Methods). Figure $5 B$ shows the data plotted in a manner that illustrates the lack of effect of chronic treatment on BK channel voltage sensitivity. The reciprocal of the slope of the $\ln \left(P_{\mathrm{o}}\right)-V$ relationship at low $P_{\mathrm{o}}$ in the presence of $10 \mu \mathrm{M}$ free$\mathrm{Ca}^{2+}$ indicated that the voltage necessary to produce an $e$-fold change in open probability was similar in naive $(28 \pm 1.22 \mathrm{mV})$ and chronic terminals $(29 \pm 1.21 \mathrm{mV}$, see Materials and Methods).

We compared the calcium sensitivity of BK channels from naive and chronic explants. This is illustrated by the plot of $V_{0.5}$ (in millivolts) as a function of free-Ca ${ }^{2+}$, in which $V_{0.5}$ decreases as $\left[\mathrm{Ca}^{2+}\right]_{\mathrm{i}}$ increases (Fig. $5 C$ ). We observed no difference between the naive and the chronic group. We also calculated the Hill coefficient by fitting the slope of the relationship between $N P_{\mathrm{o}}$ and $\left[\mathrm{Ca}^{2+}\right]_{\mathrm{i}}$ and found it was similar in naive (1.15) and chronic explants (1.07; plot not shown).
A
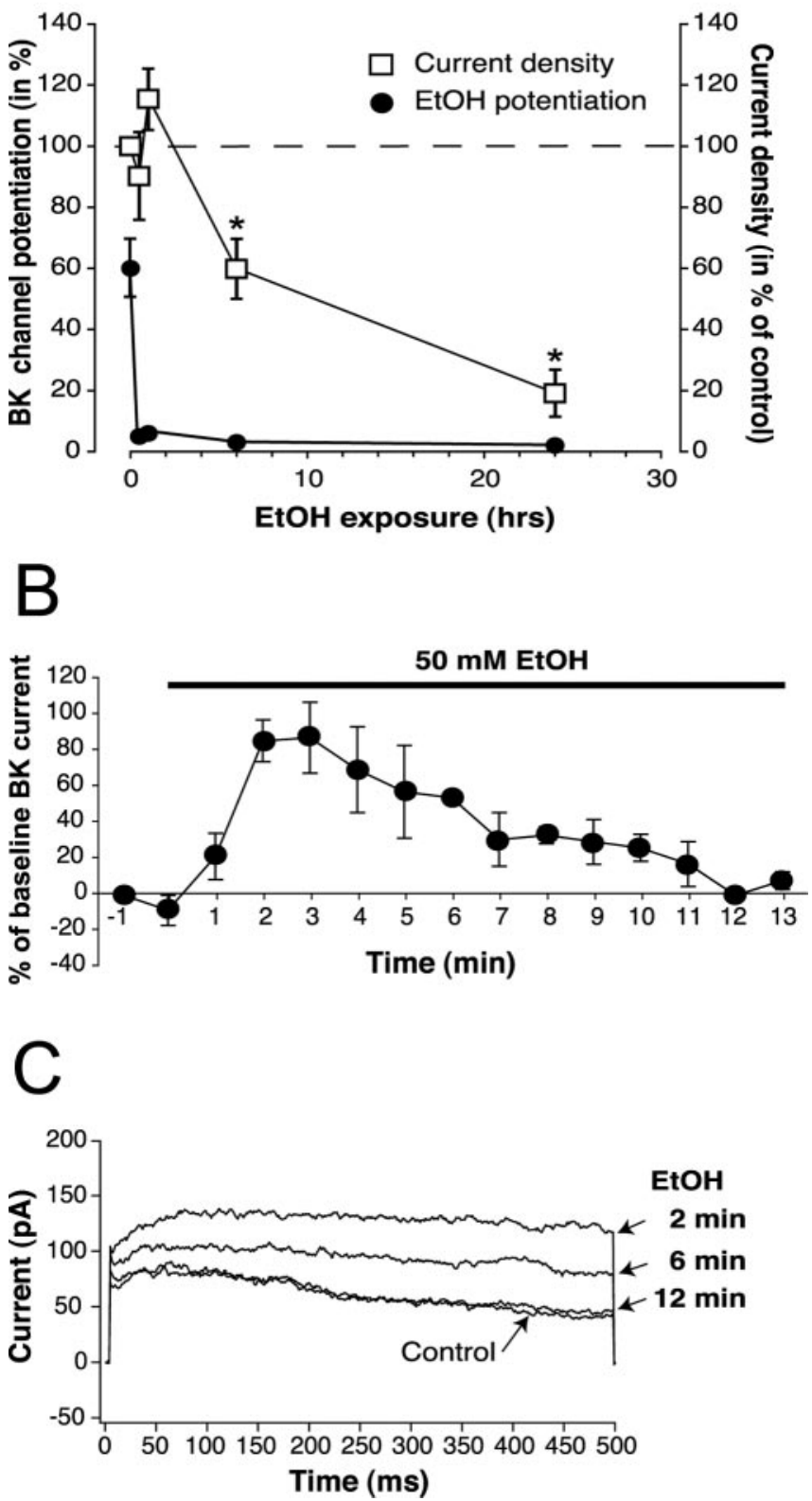

Figure 4. Time course of the development of ethanol tolerance of BK channels. A, HNS explants were cultured on Millipore inserts and exposed to ethanol for 0, 0.5, 1, 6, and $24 \mathrm{hr}$ ( $n=4-10)$. Ethanol tolerance of BK channels in the cultured NH terminals is manifested as both decreased sensitivity to ethanol, evident within 30 min of drug exposure and sustained for the entire $24 \mathrm{hr}$ observation period, and reduced BK current density, evident after $6 \mathrm{hr}$, and continuing to decrease during the $24 \mathrm{hr}$ observation period. $B$, The time course of decreased potentiation of BK current during the first few minutes was determined using the perforated patch-clamp technique with an isolated terminal from an ethanol-naive neurohypophysis ( $n=$ 2). The graph demonstrates the rapid loss of potentiation in the continued presence of ethanol. C, Representative traces of BK current from specified time points in $B$.

\section{Kinetics}

The mean open time of BK channels in the naive group was $3.5 \pm$ $0.4 \mathrm{msec}(n=6)$, which did not differ from that of BK channels from the chronic group ( $3.44 \pm 0.55 \mathrm{msec} ; n=7)$ (Fig. $5 D)$.

\section{Conductance}

Single-channel conductance was also unaffected by chronic exposure. In the naive group, BK channels had a conductance of 
$213 \pm 3.37 \mathrm{pS}(n=11)$, which is in accordance with previous reports of BK channels isolated from $\mathrm{NH}$ (Dopico et al., 1996), whereas chronically exposed terminals exhibited a BK channel conductance of $215 \pm 2.8 \mathrm{pS}(n=9)$ (Fig. $5 E)$.

Chronic ethanol causes declustering and redistribution of BK channels

The finding that single-channel properties were unaltered after the development of tolerance suggested that the decrease in current density might result from a decrease in BK channel expression in the terminal membrane. To address this question, we measured expression of $\mathrm{BK}$ channel protein in terminals, using a specific antibody directed against the main (pore-forming) $\alpha$ subunit of the channel. Although both naive and chronic explants contained BK channels in both the membrane and interior of the terminals, their distribution was different (Fig. 6A). Quantitative analysis revealed that chronic ethanol did not significantly change the total BK expression in the terminals, but shifted the expression of $\mathrm{BK}$ from the membrane to the interior (Fig. $6 B$, total). In naive explants, membrane-associated and internal $\mathrm{BK}$ channels constituted $\sim 20$ and $80 \%$, respectively, of the total BK expressed in these terminals. After chronic ethanol treatment, many more BK channels were found in the interior (94\%), whereas membrane-expressed BK channels comprised only $6 \%$ of the total BK. Thus, chronic ethanol treatment caused a significant $(p<0.05)$ decrease in the proportion of BK channels localized in the membrane of neurohypophysial terminals and a significant $(p<0.05)$ increase in the proportion of $\mathrm{BK}$ channel present in the interior (Fig. $6 \mathrm{~B}$, bottom panels).

In addition to $\mathrm{BK}$ channel redistribution, we also found that chronic ethanol disturbed the expression pattern of BK channels in the terminal membrane. In terminals obtained from naive explants, BK channels were present mainly in clusters, whereas in the membrane of the terminals from chronic explants, clusters were rarely seen, and BK expression was more diffuse. Quantitative analysis showedthat in naive terminals, BK clustersaveraged 6.5 per $100 \mu \mathrm{m}^{2}$ of terminal membrane (Fig. 7A), whereas in terminals isolated from chronic explants, clusters were observed in less than half of the terminals (43\%), and when present, averaged only 1 per $100 \mu \mathrm{m}^{2}$ (Fig. $7 A$ ) $(p<0.003)$. In the remaining $57 \%$ of chronic terminals, BK channels (although present in the membrane) were not clustered. Thus, chronic ethanol caused declustering of BK channels in the membrane of neuronal terminals.

Chronic ethanol decreases BK channel density in clusters Next, we determined whether BK channel density in clusters was altered after chronic ethanol treatment. Using confocal sections (in which clusters appeared oval-shaped), the dimensions of each
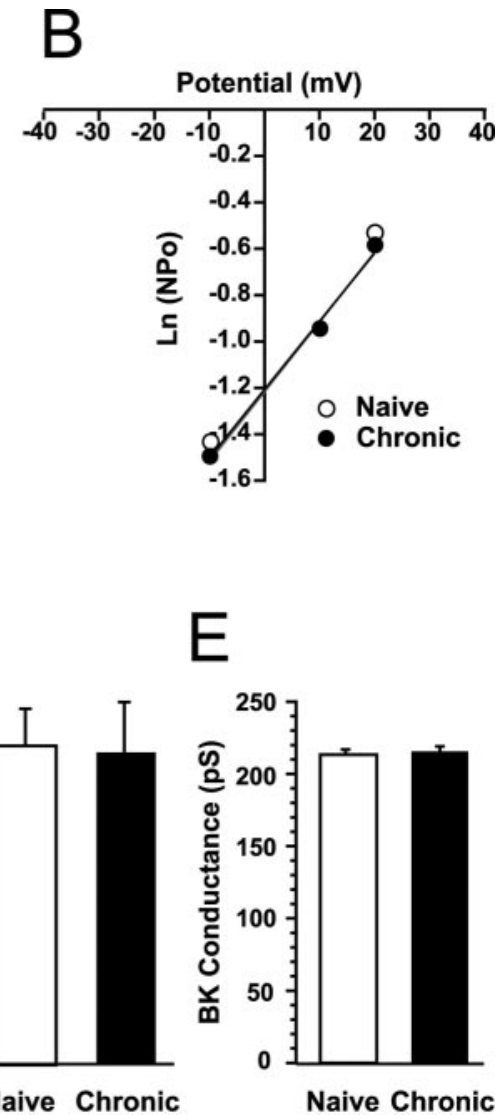

Figure 5. Chronic ethanol does not alter $B K$ channel characteristics. $A$, Normalized $N P_{0}$ as a function of voltage at three different $\left[\mathrm{Ca}^{2+}\right]_{\mathrm{i}}$ in naive (open symbols) and chronic (filled symbols) BK channels were fitted with a Boltzmann relationship of the type: $P_{0}=\left(1+\exp -K\left(V-V_{0.5}\right)\right)^{-1}$, where $K$ is the logarithmic potential sensitivity, and $V_{0.5}$ the potential at which $P_{0}$ is haximal. At each calcium concentration, naive and chronic $B K$ channels are very similar. The $P_{0}-V$ curve is shifted similarly along the voltage axis to more negative potentials as $\left[\mathrm{Ca}^{2+}\right]_{\mathrm{i}}$ is increased. $B$, Data plotted in a manner that illustrates the lack of fect of chronic treatment on $B K$ channel voltage sensitivity. The reciprocal of the slope of the $\ln \left(P_{0}\right)-V$ relationship at low $P_{0}$ in in naive $(28+1.22 \mathrm{mV})$ and chronic terminals $(29+1.21 \mathrm{mV}) . C, V_{0.5}$ values, obtained from Boltzmann fits displayed in $A$ (dashed line), are now plotted as a function of $\left[\mathrm{Ca}^{2+}\right]_{\mathrm{i}}$ on a logarithmic scale. Data points are fitted by a linear regression $(r=$ 0.99). The leftward shift in $V_{0.5}$ as $\left[\mathrm{Ca}^{2+}\right]_{\mathrm{i}}$ increases is very similar in naive and chronic $B K$ channels. D, The averaged mean open time of BK channels from naive $(n=6)$ and chronic explants $(n=7)$ are not different. Mean open time was calculated based on milliseconds), $X_{0}$ number of openings]. $E$, The mean BK channel conductance from naive $(n=12)$ and chronic $(n=11)$ terminals obtained by fitting $/-V$ plots (Fig. 2 C) are not different.

cluster along the $X, Y$, and $Z$ axes (Fig. $7 B$ ), and the intensity of BK channel expression in each section were determined. The dimensions of clusters in naive terminals $(n=40)(X, Y$, and $Z$ measurements) were $367 \pm 82,261 \pm 56$, and $843 \pm 175 \mathrm{~nm}$, respectively, and did not differ significantly from the corresponding values obtained from ethanol-treated terminals $(n=8)$ (397 \pm $55,234 \pm 52$, and $834 \pm 38 \mathrm{~nm}$ ). However, although the size of clusters remained the same, the intensity of BK signal in each cluster was decreased along all axes after chronic ethanol treatment (Fig. 7C). Figure 7D illustrates that $24 \mathrm{hr}$ chronic ethanol treatment of HNS explants caused a significant $(p<0.05)$ decrease in BK channel density in clusters in neuronal terminals.

\section{Discussion}

The present study examines the effects of ethanol on BK channel expression and function in CNS terminals from cultured HNS explants. The HNS, through the release of the peptide hormones AVP and OXT, plays a critical role in physiology and behavior. In addition to its physiological role in the circulatory system and 

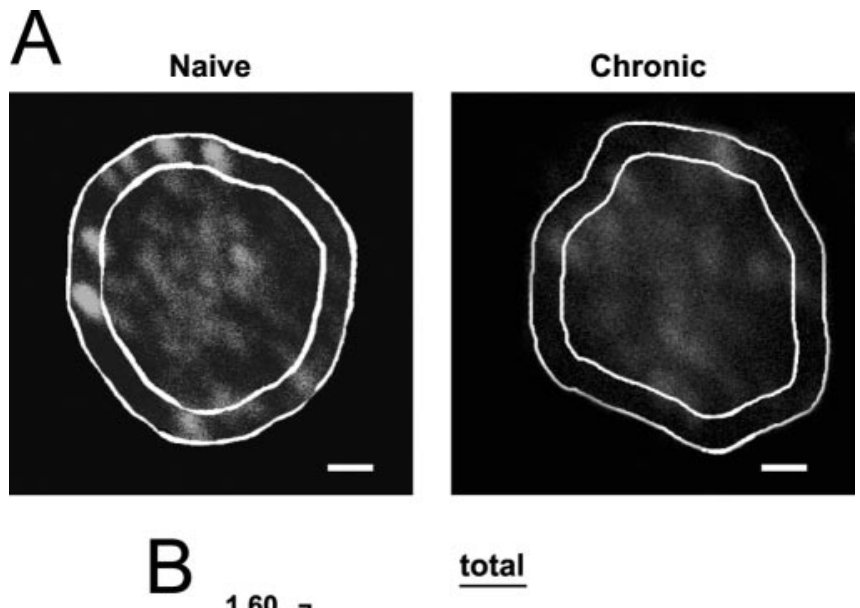

total
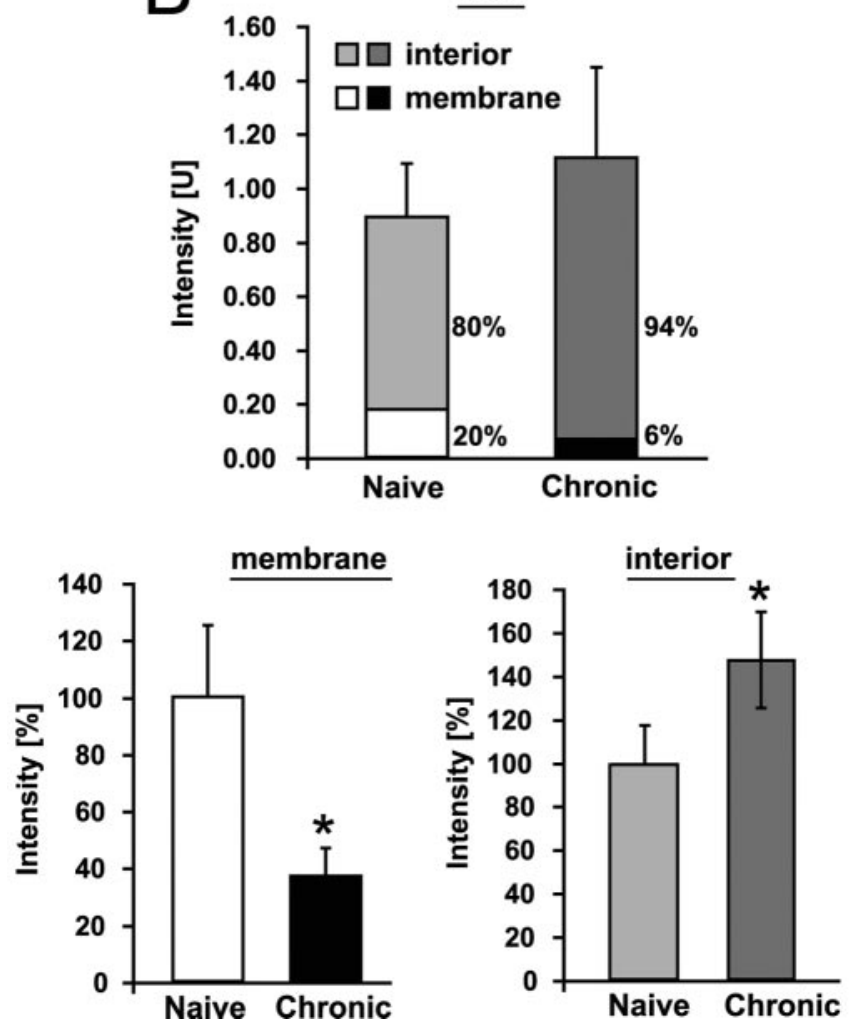

Figure 6. Chronic ethanol changes distribution of $B K$ channels in neuronal terminals. $A$, Representative immunofluorescent confocal images (in a grayscale) of naive and chronic HNS terminals stained for BK pore-forming $\alpha$ subunit. Neurohypophysial terminals were homogenized and dropped onto a poly---lysine-coated Petri dish, fixed in paraformaldehyde, and double-labeled against AVP-OXT and BK channel $\alpha$ subunit. Laser-scanning fluorescence and DIC images were acquired simultaneously using a Leica laser-scanning microscope. Boundaries of the terminals were determined using DIC image, and each section of the terminal was divided into a membrane and an interior regions based on a membrane-associated fluorescence signal width of $0.45 \mu \mathrm{m}$ (Chiu et al., 2002). Scale bar, $700 \mathrm{~nm}$. B, Quantitative analysis in naive ( $n=$ 12 ) and chronic $(n=14)$ terminals showed that total BK expression in NH terminals is not significantly changed after chronic ethanol treatment (total). In contrast, membraneassociated BK expression decreases (membrane), whereas the amount of BK expressed in the interior increases (interior) after chronic ethanol treatment. ${ }^{*} p<0.05$.

urinary tract (Lemos, 2001), AVP has important functions in learning and memory and in the development of alcohol tolerance (Koob et al., 1989; Hoffman et al., 1990; Reghunandanan et al., 1998).

Earlier findings indicated that the acute actions of ethanol differ between cellular compartments of magnocellular neurons, with BK channels located in the terminals potentiated by ethanol,
A

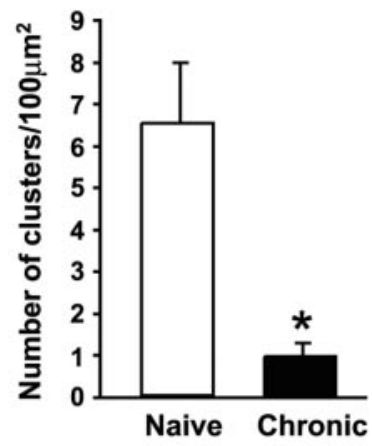

C
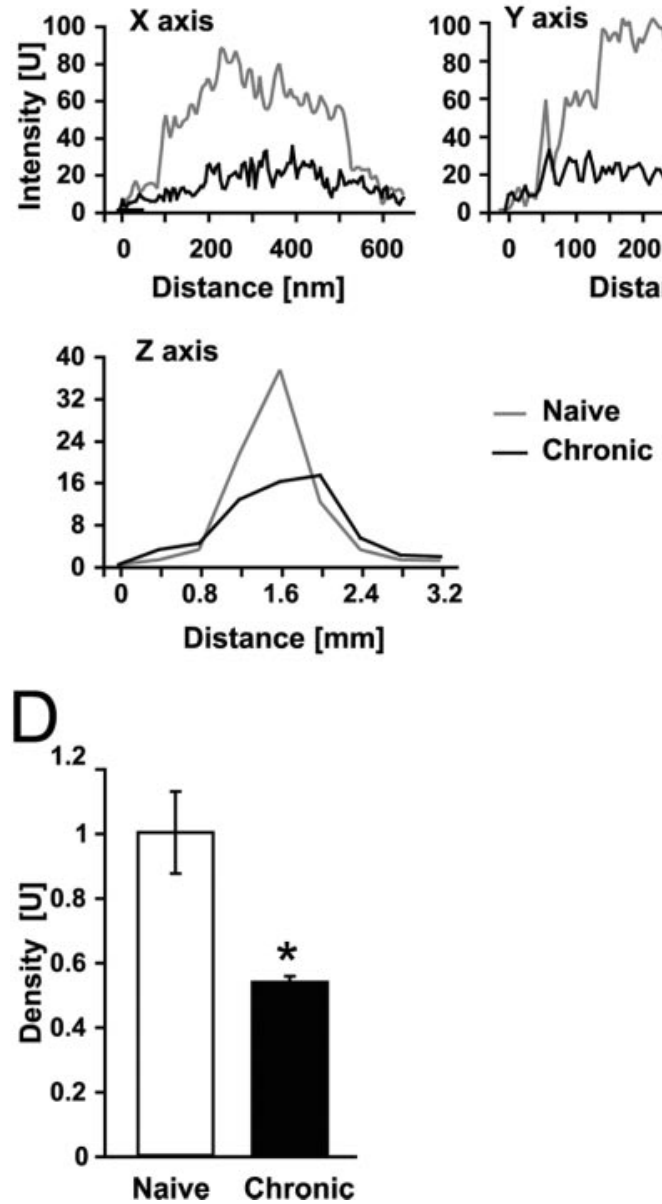

Figure 7. Chronic ethanol causes declustering of BK channels and reduces density of BK channels in clusters. Confocal images from naive and chronic terminals were used in this study. The number of BK clusters, their size, and the intensity profiles were determined using Leica quantification software (version 2.00; Microsystems). A, Quantification of the number of clusters in naive $(n=12)$ and chronic $(n=14)$ terminals shows a significant decrease after chronic ethanol treatment. $B$, Representative images of a naive and a chronic cluster showing axes used to determine three-dimensional density of BK in clusters. $C$, Intensity profiles of BK clusters in naive and chronic terminals measured along $X, Y$, and $Z$ axes as shown in B. D, Quantification of BK density in naive $(n=40)$ and chronic $(n=8)$ clusters indicates that chronic ethanol causes an approximately twofold decrease in the BK density per cluster. $\left({ }^{*} p<0.05\right)$.

whereas BK channels in the cell bodies were insensitive to ethanol (Dopico et al., 1999b). Single-channel recordings showed that the acute actions of ethanol targeted the gating of the channels: the contribution of long openings to the total time spent in the open 
state is increased, the average duration of the fast openings is slightly increased, and long closures disappear in the presence of the drug (Dopico et al., 1996, 1998). Other functional parameters of the channel were unaffected. Previous studies of the development of alcohol tolerance in neuronal channels in the HNS were performed using an intact animal exposed to an ethanolcontaining diet for several weeks. Chronic exposure reduced the alcohol potentiation and decreased the current density of the BK channel (Knott et al., 2002). The use of the whole animal is limiting in a few important aspects. First, studies of the chronology of tolerance are impeded by the long period necessary for the buildup of blood alcohol levels, using the sucrose fade technique (Knott et al., 2000). Second, it is impossible to separate actions of the drug directly on channels within HNS neurons (intrinsic tolerance) from actions elsewhere in the intact animal and nervous system that secondarily affect neuronal function in HNS neurons (extrinsic tolerance). Use of the HNS explant allows precise control over dosage and time of exposure to the drug and determination of which form of tolerance is present in the neuronal terminals in the HNS.

Here, we first demonstrate the successful preparation of a viable HNS explant, harvested from the adult rat brain, which can be cultured for a time suitable to study chronic ethanol effects. HNS explants, like organotypic cultures, have many advantages over cell cultures, including preservation of the threedimensional architecture found in vivo (Sladek and Knigge, 1977; Gahwiler, 1981, 1988). Electrical properties of individual neurons, as well as populations of neurons, are remarkably similar to those seen in situ (Dingledine et al., 1980; Dudek et al., 1980). Although afferent connections originating outside the explant are lost, local synaptic connections and the microenvironment of neurosecretory cells are maintained. In the SON, the majority of synapses involve presynaptic elements originating within the structure, and the density of synaptic boutons is unaffected for at least $7 \mathrm{~d}$ after surgical separation of the SON from the rest of the brain (Zaborszky et al., 1975). To compare findings in the explant with those obtained previously in the intact animal and to avoid the complication of drug actions on a developing system, we developed techniques for culturing explants obtained from animals 3 weeks or older, at which time development of the HNS is complete (Galabov and Schiebler, 1978; Choy and Watkins, 1979; Krisch, 1980; Chevaleyre et al., 2000, 2001). We optimized dissection techniques and culturing conditions, including preparation of a thin explant allowing adequate penetration of oxygen and nutrients throughout the tissue, while avoiding disruption of the axonal path. Neuronal cell death was low $(<3 \%)$, and more importantly, did not progress in culture. In this study, HNS explant terminals were analyzed on the third day in culture, because tolerance was apparent at this time, although cell viability, determined by morphological criteria, appeared not to be reduced, even after 5 weeks in culture (data not shown). Thus, observed changes in BK channel potentiation and distribution in the $\mathrm{NH}$ terminal do not result from changes in cell health.

An important finding in this study was the identification of the intrinsic character of tolerance to ethanol in BK channels of neuronal terminals. The explants did not contain other brain structures [e.g., organum vasculosum laminas terminalis (OVLT); suprachiasmatic nucleus (SCN)], which could modulate the function of magnocellular neurons. The actions of elements originating outside of the brain were also eliminated. Thus, molecular mechanisms of tolerance are contained within the HNS.

Ethanol tolerance observed in the cultured explant and man-

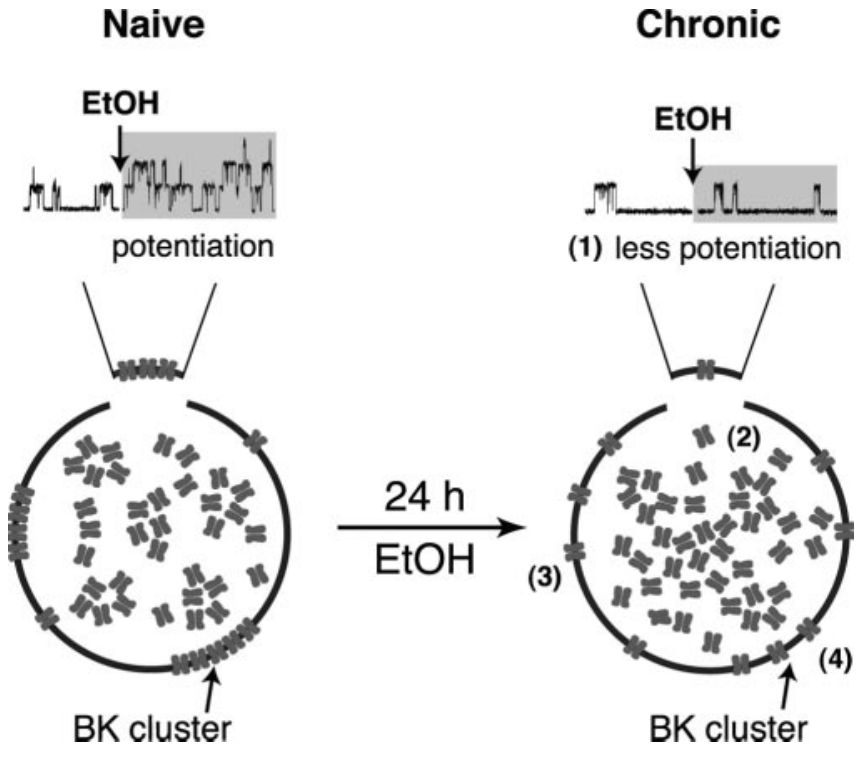

Figure 8. Summary of modulation of BK channel function and distribution in neuronal terminals by chronic ethanol. After $24 \mathrm{hr}$ exposure, BK channels are (1) less potentiated by acute challenge, (2) more internalized, (3) less clustered in the membrane, and (4) less dense within remaining clusters.

ifested as both diminished potentiation and decreased current density, qualitatively resembled the changes observed in terminals obtained from animals chronically exposed to the drug for 3 weeks. However, the explant allowed us to establish that these two forms of tolerance represent distinct processes. The reduced potentiation was very rapid and evident within a few minutes of exposure, whereas the reduced current density did not near completion until $24 \mathrm{hr}$ of exposure. Neither form of tolerance required the 3 week exposure period that was necessary to obtain stable blood alcohol levels in the ingesting animal (Knott et al., 2000). The rapid appearance of reduced potentiation suggests direct or indirect post-translational modifications of BK channels (e.g., phosphorylation) rather than genetic reorganization, especially because terminals from which BK currents were recorded are located in the neurohypophysis, whereas cell bodies lie in the hypothalamus a few millimeters away. On the other hand, in the development of long-term tolerance, we cannot exclude that translational or transcriptional processes are involved as well. It is possible that, analogous to memory mechanisms (Kandell, 1991), there is a short-term tolerance that is quickly observed, which is then supplanted by a longer-term process to maintain reduced potentiation for the weeks it was evident in the animal studies. A number of recent findings invoke changes in factors such as $\mathrm{CREB}$ and $\Delta \mathrm{C}$-fos in encoding long-lasting nervous system changes after drug exposure (Nestler, 2002; McClung and Nestler, 2003; Chao and Nestler, 2004). Alternatively, short-term posttranslational modifications might be "locked-in" by changes in intermediary molecules such as CAM-kinase II or IV.

A combination of immunohistochemistry and single-channel recording indicated that the decreased BK current density resulted from a reduced number of membrane channels, rather than from a change in single-channel properties (see model in Fig. 8). Alteration of the number of channels expressed in the terminal membrane serves as an important mechanism regulating synaptic efficacy and neurotransmitter release (Man et al., 2000; Shuai and Jung, 2003). A recent report (Kumar et al., 2003) shows that after chronic administration of ethanol to rats, 
$\mathrm{GABA}_{\mathrm{A}}$ receptors were also internalized. Certain agonists of $\mu$-opioid receptors modulate the number of morphine receptors in the plasma membrane by increasing ligand-induced receptor internalization (Sternini et al., 1996; Keith et al., 1998; Trafton et al., 2000). Interestingly, the time course of these internalization processes typically occurs within minutes rather than hours, as observed in the $\mathrm{NH}$ terminal. This suggests a mechanism of ethanol-induced internalization different than opiate drugs. Interestingly, ethanol-induced internalization seems to be specific for certain channels, because as we reported previously using the whole animal ingestion model (Knott et al., 2002), current density of BK and L-type calcium channels is altered, whereas the density of other voltage-gated calcium currents and the fast inactivating transient potassium current $\left(I_{\mathrm{A}}\right)$ is not changed after chronic ethanol treatment.

Chronic ethanol treatment resulted in the declustering and lateral diffusion of BK channels in the terminal membrane (Fig. 8). Clustering of another potassium channel, Kv1.4, is essential for suppressing internalization and degradation of that channel and serves as a mechanism for the regulation of channel density in the plasma membrane (Jugloff et al., 2000), suggesting that the declustering and internalization of the BK channel observed in the NH terminal may be causally related.

Thus, the development of BK channel tolerance to ethanol consists of two distinct components: a rapid decrease of potentiation by ethanol of individual channels and a slower process of diminishing channel density on the CNS terminal surface. The cultured HNS explant offers a powerful preparation in which to describe and study the mechanisms underlying tolerance in CNS terminals.

\section{References}

Armstrong WE (1995) Morphological and electrophysiological classification of hypothalamic supraoptic neurons. Prog Neurobiol 47:291-339.

Ben Barak Y, Russell JT, Whitnall MH, Ozato K, Gainer H (1985) Neurophysin in the hypothalamo-neurohypophysial system. I. Production and characterization of monoclonal antibodies. J Neurosci 5:81-97.

Bonde C, Noraberg J, Zimmer J (2002) Nuclear shrinkage and other markers of neuronal cell death after oxygen-glucose deprivation in rat hippocampal slice cultures. Neurosci Lett 327:49-52.

Brewer GJ (1997) Isolation and culture of adult rat hippocampal neurons. J Neurosci Methods 71:143-155.

Burbach JP, Luckman SM, Murphy D, Gainer H (2001) Gene regulation in the magnocellular hypothalamo-neurohypophysial system. Physiol Rev 81:1197-1267.

Cazalis M, Dayanithi G, Nordmann JJ (1987) Hormone release from isolated nerve endings of the rat neurohypophysis. J Physiol (Lond) 390:55-70.

Chao J, Nestler EJ (2004) Molecular neurobiology of drug addiction. Annu Rev Med 55:113-132.

Chevaleyre V, Dayanithi G, Moos FC, Desarmenien MG (2000) Developmental regulation of a local positive autocontrol of supraoptic neurons. J Neurosci 20:5813-5819.

Chevaleyre V, Moos FC, Desarmenien MG (2001) Correlation between electrophysiological and morphological characteristics during maturation of rat supraoptic neurons. Eur J Neurosci 13:1136-1146.

Chiu CS, Jensen K, Sokolova I, Wang D, Li M, Deshpande P, Davidson N, Mody I, Quick MW, Quake SR, Lester HA (2002) Number, density, and surface/cytoplasmic distribution of GABA transporters at presynaptic structures of knock-in mice carrying GABA transporter subtype 1-green fluorescent protein fusions. J Neurosci 22:10251-10266.

Choy VJ, Watkins WB (1979) Maturation of the hypothalamo-neurohypophysial system. I. Localization of neurophysin, oxytocin and vasopressin in the hypothalamus and neural lobe of the developing rat brain. Cell Tissue Res 197:325-336.

Dingledine R, Dodd J, Kelly JS (1980) The in vitro brain slice as a useful neurophysiological preparation for intracellular recording. J Neurosci Methods 2:323-362.
Dopico AM, Lemos JR, Treistman SN (1996) Ethanol increases the activity of large conductance, $\mathrm{Ca}^{(2+)}$-activated $\mathrm{K}+$ channels in isolated neurohypophysial terminals. Mol Pharmacol 49:40-48.

Dopico AM, Anantharam V, Treistman SN (1998) Ethanol increases the activity of $\mathrm{Ca}^{(++)}$-dependent $\mathrm{K}^{+}$(mslo) channels: functional interaction with cytosolic $\mathrm{Ca}^{++}$. J Pharmacol Exp Ther 284:258-268.

Dopico AM, Chu B, Lemos JR, Treistman SN (1999a) Alcohol modulation of calcium-activated potassium channels. Neurochem Int 35:103-106.

Dopico AM, Widmer H, Wang G, Lemos JR, Treistman SN (1999b) Rat supraoptic magnocellular neurones show distinct large conductance, $\mathrm{Ca}^{2+}$-activated $\mathrm{K}^{+}$channel subtypes in cell bodies versus nerve endings. J Physiol (Lond) 519:101-114.

Dudek FE, Hatton GI, MacVicar BA (1980) Intracellular recordings from the paraventricular nucleus in slices of rat hypothalamus. J Physiol (Lond) 301:101-114

Fabiato A (1988) Computer programs for calculating total from specified free or free from specified total ionic concentrations in aqueous solutions containing multiple metals and ligands. Methods Enzymol 157:378-417.

Fujii T, Baumgartl H, Lubbers DW (1982) Limiting section thickness of guinea pig olfactory cortical slices studied from tissue $\mathrm{pO} 2$ values and electrical activities. Pflügers Arch 393:83-87.

Gahwiler BH (1981) Nerve cells in organotypic cultures. JAMA 245: $1858-1859$.

Gahwiler BH (1988) Organotypic cultures of neural tissue. Trends Neurosci 11:484-489.

Galabov P, Schiebler TH (1978) The ultrastructure of the developing neural lobe. Cell Tissue Res 189:313-329.

Gundersen HJ, Jensen EB (1987) The efficiency of systematic sampling in stereology and its prediction. J Microsc 147:229-263.

Gundersen HJ, Jensen EB, Kieu K, Nielsen J (1999) The efficiency of systematic sampling in stereology-reconsidered. J Microsc 193:199-211.

Harding AJ, Ng JL, Halliday GM, Oliver J (1995) Comparison of the number of vasopressin-producing hypothalamic neurons in rats and humans. J Neuroendocrinol 7:629-636.

Hoffman PL, Ishizawa H, Giri PR, Dave JR, Grant KA, Liu LI, Gulya K, Tabakoff B (1990) The role of arginine vasopressin in alcohol tolerance. Ann Med 22:269-274.

House SB, Thomas A, Kusano K, Gainer H (1998) Stationary organotypic cultures of oxytocin and vasopressin magnocellular neurones from rat and mouse hypothalamus. J Neuroendocrinol 10:849-861.

Jugloff DG, Khanna R, Schlichter LC, Jones OT (2000) Internalization of the Kv1.4 potassium channel is suppressed by clustering interactions with PSD-95. J Biol Chem 275:1357-1364.

Kalant H (1998) Res on tolerance: what can we learn from history? Alcohol Clin Exp Res 22:67-76.

Kandell ER (1991) Learning and memory. In: Principles of neural science (Kandell ER, Schwartz JH, Jessell TM, eds), pp 1011-1023. New York: Simon and Schuster.

Keith DE, Anton B, Murray SR, Zaki PA, Chu PC, Lissin DV, MonteilletAgius G, Stewart PL, Evans CJ, von Zastrow M (1998) Mu-opioid receptor internalization: opiate drugs have differential effects on a conserved endocytic mechanism in vitro and in the mammalian brain. Mol Pharmacol 53:377-384

Knott TK, Dayanithi G, Coccia V, Custer EE, Lemos JR, Treistman SN (2000) Tolerance to acute ethanol inhibition of peptide hormone release in the isolated neurohypophysis. Alcohol Clin Exp Res 24:1077-1083.

Knott TK, Dopico AM, Dayanithi G, Lemos J, Treistman SN (2002) Integrated channel plasticity contributes to alcohol tolerance in neurohypophysial terminals. Mol Pharmacol 62:135-142.

Koob GF, Lebrun C, Bluthe RM, Dantzer R, Le Moal M (1989) Role of neuropeptides in learning versus performance: focus on vasopressin. Brain Res Bull 23:359-364.

Krisch B (1980) Electron microscopic immunocytochemical investigation on the postnatal development of the vasopressin system in the rat. Cell Tissue Res 205:453-471.

Kumar S, Kralic JE, O'Buckley TK, Grobin AC, Morrow AL (2003) Chronic ethanol consumption enhances internalization of alphal subunitcontaining GABAA receptors in cerebral cortex. J Neurochem $86: 700-708$.

Lemos JR (2001) Magnocellular neurons. In: Nature encyclopedia of life sciences. A176:1-5. New York: Nature Publishing Group. www.els.net.

Madeira MD, Sousa N, Lieberman AR, Paula-Barbosa MM (1993) Effects of 
chronic alcohol consumption and of dehydration on the supraoptic nucleus of adult male and female rats. Neuroscience 56:657-672.

Man HY, Lin JW, Ju WH, Ahmadian G, Liu L, Becker LE, Sheng M, Wang YT (2000) Regulation of AMPA receptor-mediated synaptic transmission by clathrin-dependent receptor internalization. Neuron 25:649-662.

Marciano FF, Wiegand SJ, Sladek Jr JR, Gash DM (1989) Fetal hypothalamic transplants promote survival and functional regeneration of axotomized adult supraoptic magnocellular neurons. Brain Res 483:135-142.

Marty A (1981) Ca-dependent K channels with large unitary conductance in chromaffin cell membranes. Nature 291:497-500.

McClung CA, Nestler EJ (2003) Regulation of gene expression and cocaine reward by CREB and DeltaFosB. Nat Neurosci 6:1208-1215.

McManus OB (1991) Calcium-activated potassium channels: regulation by calcium. J Bioenerg Biomembr 23:537-560.

Nestler EJ (2002) Common molecular and cellular substrates of addiction and memory. Neurobiol Learn Mem 78:637-647.

Nicholson C, Hounsgaard J (1983) Diffusion in the slice microenvironment and implications for physiological studies. Fed Proc 42:2865-2868.

Pietrzykowski AZ, Knott TK Tully KL Custer EE Lemos JR Treistman SN (2001) Long-term hypothalamic-neurohypophysial explant culture for study of neurosecretion and ethanol tolerance. Soc Neurosci Abstr 27:179.12.

Pietrzykowski AZ, Martin G, Puig S, Treistman SN (2003) Mechanisms underlying tolerance to chronic ethanol of BK channels in the terminals of rat posterior pituitary. Soc Neurosci Abstr 29:108.12.

Reghunandanan V, Reghunandanan R, Mahajan KK (1998) Arginine vasopressin as a neurotransmitter in brain. Indian J Exp Biol 36:635-643.

Rhodes CH, Morrell JI, Pfaff DW (1981) Immunohistochemical analysis of magnocellular elements in rat hypothalamus: distribution and numbers of cells containing neurophysin, oxytocin, and vasopressin. J Comp Neurol 198:45-64.

Rossi NF (2004) Regulation of vasopressin secretion by ETA and ETB receptors in compartmentalized rat hypothalamo-neurohypophysial explants. Am J Physiol Endocrinol Metab 286:E535-E541.

Ruela C, Sousa N, Madeira MD, Paula-Barbosa MM (1994) Stereological study of the ultrastructural changes induced by chronic alcohol consumption and dehydration in the supraoptic nucleus of the rat hypothalamus. J Neurocytol 23:410-421.

Shuai JW, Jung P (2003) Optimal ion channel clustering for intracellular calcium signaling. Proc Natl Acad Sci USA 100:506-510.

Silverman AJ, Zimmerman EA (1983) Magnocellular neurosecretory system. Annu Rev Neurosci 6:357-380.
Sladek CD, Knigge KM (1977) Osmotic control of vasopressin release by rat hypothalamo-neurohypophyseal explants in organ culture. Endocrinology 101:1834-1838.

Somponpun SJ, Sladek CD (2004) Depletion of oestrogen receptor-beta expression in magnocellular arginine vasopressin neurones by hypovolaemia and dehydration. J Neuroendocrinol 16:544-549.

Sternini C, Spann M, Anton B, Keith Jr DE, Bunnett NW, von Zastrow M, Evans C, Brecha NC (1996) Agonist-selective endocytosis of mu opioid receptor by neurons in vivo. Proc Natl Acad Sci USA 93:9241-9246.

Stoppini L, Buchs PA, Muller D (1991) A simple method for organotypic cultures of nervous tissue. J Neurosci Methods 37:173-182.

Swaab DF, Nijveldt F, Pool CW (1975) Distribution of oxytocin and vasopressin in the rat supraoptic and paraventricular nucleus. J Endocrinol 67:461-462.

Thorn PJ, Wang XM, Lemos JR (1991) A fast, transient $\mathrm{K}^{+}$current in neurohypophysial nerve terminals of the rat. J Physiol (Lond) 432:313-326.

Trafton JA, Abbadie C, Marek K, Basbaum AI (2000) Postsynaptic signaling via the [mu]-opioid receptor: responses of dorsal horn neurons to exogenous opioids and noxious stimulation. J Neurosci 20:8578-8584.

Vutskits L, Bartanusz V, Schulz MF, Kiss JZ (1998) Magnocellular vasopressinergic neurons in explant cultures are rescued from cell death by ciliary neurotrophic factor and leukemia inhibiting factor. Neuroscience 87:571-582.

Wang G, Thorn P, Lemos JR (1992) A novel large-conductance $\mathrm{Ca}^{(2+)}$ activated potassium channel and current in nerve terminals of the rat neurohypophysis. J Physiol (Lond) 457:47-74.

West MJ, Slomianka L, Gundersen HJ (1991) Unbiased stereological estimation of the total number of neurons in the subdivisions of the rat hippocampus using the optical fractionator. Anat Rec 231:482-497.

Whitnall MH, Key S, Ben Barak Y, Ozato K, Gainer H (1985) Neurophysin in the hypothalamo-neurohypophysial system. II. Immunocytochemical studies of the ontogeny of oxytocinergic and vasopressinergic neurons. J Neurosci 5:98-109.

Xiang Z, Hrabetova S, Moskowitz SI, Casaccia-Bonnefil P, Young SR, Nimmrich VC, Tiedge H, Einheber S, Karnup S, Bianchi R, Bergold PJ (2000) Long-term maintenance of mature hippocampal slices in vitro. J Neurosci Methods 98:145-154.

Zaborszky L, Leranth C, Makara GB, Palkovits M (1975) Quantitative studies on the supraoptic nucleus in the rat. II. Afferent fiber connections. Exp Brain Res 22:525-540. 